DOI: $10.12957 /$ teias.2022.53433

\title{
A SOCIOLOGIA E A FORMAÇÃO DA CIDADANIA DOS ALUNOS DO ENSINO MÉDIO
}

\author{
Maria das Dôres de Sousa \\ Luciana Silva Dias \\ Douglas Pereira da Costa
}

Resumo

O presente artigo investiga as perspectivas dos alunos do ensino médio sobre a contribuição da disciplina de Sociologia para a formação da cidadania. Entende-se que as aulas de Sociologia podem ser um espaço propício para elucidar a concepção de cidadania e como exercê-la, pois instiga os educandos a desenvolverem um pensamento crítico e reflexivo que favorece uma compreensão dos seus direitos e deveres para com a sociedade. Trata-se de um estudo de cunho qualitativo. Para coleta de dados, foi aplicado um questionário estruturado junto a 50 alunos de cinco escolas estaduais de Picos-PI. Para apreciação dos dados, recorreu-se à Análise de Conteúdo em Bardin (2011). Verifica-se, com este estudo, que os educandos consideram a disciplina de Sociologia um componente curricular necessário para a compreensão da sociedade em que vivem, tornando-os cidadãos mais conscientes da legitimidade de seus direitos e deveres e das desigualdades sociais que marcam a sociedade movida pelo capitalismo.

Palavras-chave: sociologia; cidadania; ensino médio.

\section{SOCIOLOGY AND CITIZENSHIP FORMATION OF HIGH SCHOOL} STUDENTS

Abstract

This article investigates the perspectives of high school students on the contribution of the discipline of Sociology to the formation of citizenship. It is understood that Sociology classes can be a favorable space to elucidate the concept of citizenship and how to exercise it, as it encourages students to develop a critical and reflective thinking that favors an understanding of their rights and duties towards society. This is a qualitative study. For data collection, a structured questionnaire was applied to 50 students from five state schools in Picos-PI. To analyze the data, Content Analysis in Bardin (2011) was used. It is verified with this study that the students consider the discipline of Sociology a necessary curricular component for the understanding of the society in which they live, making them more aware of the legitimacy of their rights and duties and of the social inequalities that mark the society driven by capitalism.

Keywords: sociology; citizenship; high school.

\section{FORMACIÓN DE SOCIOLOGÍA Y CIUDADANÍA DE ESTUDIANTES DE ESCUELA SECUNDARIA}

Resumen

Este artículo investiga las perspectivas de los estudiantes de secundaria sobre la contribución de la disciplina de la sociología a la formación de la ciudadanía. Se entiende que las clases de sociología pueden ser un espacio favorable para dilucidar el concepto de ciudadanía y cómo ejercerlo, ya que alienta a los estudiantes a desarrollar un pensamiento crítico y reflexivo que favorezca la comprensión de sus derechos y deberes hacia la sociedad. Este es un estudio cualitativo. Para la recolección de datos, se aplicó un cuestionario estructurado a 50 estudiantes de cinco escuelas estatales en Picos-PI. Para analizar los datos, se utilizó el Análisis de contenido en Bardin (2011). Con este estudio se verifica que los estudiantes consideran que la disciplina de la sociología es un componente curricular necesario para la comprensión de la sociedad en la 
que viven, haciéndolos más conscientes de la legitimidad de sus derechos y deberes y de las desigualdades sociales que marcan a la sociedad impulsada por capitalismo.

Palabras clave: sociología; ciudadanía; escuela secundaria.

\section{INTRODUÇÃO}

Este artigo se situa como um desdobramento decorrente do projeto de pesquisa a Sociologia no Ensino Médio: historicidade e formação para a cidadania nas escolas públicas estaduais da zona urbana de Picos-PI - Universidade Federal do Piauí, Campus Senador Helvídio Nunes de Barros, entre os anos de 2015 - 2017, com o propósito de investigar se a Sociologia como disciplina de caráter científico, dotado de referencial teórico competente para a análise social, proporcionou aos alunos das escolas públicas estaduais do ensino médio da cidade de Picos-PI uma formação para a cidadania, de forma a desenvolver uma consciência crítica para que estes possam compreender as particularidades inerentes aos seus direitos e deveres. Segundo Sousa (2012, p. 64):

[...] com a concretização das DCNEM (Diretrizes Curriculares Nacionais para o Ensino Médio) a Sociologia e a Filosofia passam a estar presentes na área de Ciências Humanas e suas Tecnologias para que se cumpra a determinação expressa no artigo $36,3^{\circ}$ parágrafo da Lei Diretrizes e Base da Educação Nacional (LDB) - lei n. ${ }^{\circ}$ 9.394/96, quando diz que os educandos, ao término do Ensino Médio, demonstrem 'domínio dos conhecimentos de Filosofia e de Sociologia necessários ao exercício da cidadania’.

A regulamentação deste artigo deu-se com muita discussão e reflexão no interior do Conselho Nacional de Educação. Assim, a Sociologia foi inserida no currículo a partir da Lei 11.684, de 2 de junho de 2008, com a perspectiva de que o conhecimento sociológico possa contribuir na formação do aluno para o trabalho e para a prática social

Com a aprovação da Sociologia no ensino médio, ampliou-se o debate em torno desse componente. Contudo, o Projeto de Lei da reforma do Ensino Médio, n. ${ }^{\circ}$ 34/2016, sancionado pelo presidente da República Michel Temer no dia 16/02/2017, deixou a Sociologia em situação desfavorável, considerando que as escolas serão obrigadas a oferecer a disciplina, mas sendo facultativo ao aluno cursá-la. Um sentimento de vitória e de conquista que tomou conta de amplos setores, que há muito tempo haviam participado do processo de luta pela inclusão da disciplina nos currículos escolares, transforma-se em motivo de apreensão e novos desafios para os professores e pesquisadores da área das Ciências Sociais sobre as perspectivas de conquistas de espaços e legitimação pedagógica e científica do ensino de Sociologia na educação básica.

Vale ressaltar que, no Estado do Piauí, onde esta pesquisa foi desenvolvida, os componentes curriculares de Sociologia e Filosofia estão presentes no ensino médio desde 2002, quando a Assembleia Legislativa aprovou, em 27 de junho do mesmo ano, o Projeto de Lei n. ${ }^{\circ}$ 07/02, que tornou obrigatório o ensino das disciplinas de Sociologia e de Filosofia no ensino médio, possibilitando aos jovens um desenvolvimento crítico e reflexivo (SOUSA, 2012).

Para Santos (2002, p.42), “[...] se a disciplina de Sociologia for trabalhada de forma eficaz, provavelmente trará contribuições para a formação do cidadão, dando a ele instrumentos para o questionamento, a pesquisa e a reflexão crítica sobre a sociedade". Posicionar-se criticamente implica fazer opções sociais, situar-se como sujeito de ideias que respondem por determinados 
valores e posicionamentos. Pesquisar o ensino da Sociologia no âmbito do ensino médio, além de avaliar o impacto que esta disciplina pode causar na formação da cidadania e na consciência crítica dos educandos, amplia as possibilidades de inserção dos saberes das Ciências Sociais. Segundo Sousa (2012, p. 88), a Sociologia

[...] pode trazer grandes contribuições aos estudantes na formação de uma consciência crítica, chamando-os a se entenderem como sujeitos e protagonistas históricos, inseridos na complexidade da sociedade capitalista com uma visão mais humanística. O contato dos jovens com o conhecimento sociológico irá produzir uma concepção, uma compreensão da realidade na qual estão inseridos e da sociedade de modo geral que nenhuma outra disciplina poderá fornecer.

Desse modo, este artigo objetiva investigar as perspectivas dos alunos do ensino médio de cinco escolas públicas estaduais de Picos-PI sobre a contribuição da disciplina de Sociologia para a formação da cidadania, de forma a desenvolver uma consciência crítica para que eles possam compreender as particularidades inerentes aos seus direitos e deveres, no que diz respeito à sua constituição como cidadãos.

\section{REFERENCIAL TEÓRICO}

A introdução da Sociologia no ensino médio tem um papel fundamental na formação dos jovens, principalmente no que diz respeito à construção da cidadania, pois conforme a Lei de Diretrizes e Bases da Educação (LDB), nº. 9394/96, artigo 36, enfatizada anteriormente, a disciplina de Sociologia tem como finalidade despertar nos educandos conhecimentos sociológicos que possibilitem uma formação para a cidadania.

Observa-se que esse componente curricular objetiva desenvolver uma perspectiva sociológica crítica nos alunos, de modo que possam compreender a sociedade para além do senso comum, que não aceitem as exigências impostas de forma cega, mas tenham consciência de seu papel ativo na sociedade e dos cumprimentos de seus deveres.

Embora não seja objetivo deste estudo discutir sobre o contexto histórico da Sociologia no Brasil, é importante fazer uma breve apresentação da sua trajetória, que segue a seguinte periodização: período de institucionalização da disciplina no ensino secundário (1891-1941); período de ausência da Sociologia como disciplina obrigatória (1941-1981); período de reinserção gradativa da Sociologia no Ensino Médio, por meio de projetos de lei estaduais (1982-2001); período em que se inicia a promulgação da Lei 11.684, de 2 de junho de 2008, que estabelece a obrigatoriedade das disciplinas de Sociologia e Filosofia nas três séries de todas as escolas do ensino médio no Brasil (SOUSA, 2012; SANTOS, 2004). Todavia, com o Projeto de Lei da reforma do Ensino Médio $n^{\circ}$. 34/2016, sancionado em 16/02/2017, a obrigatoriedade da Sociologia ficou ameaçada, tendo em vista que foi concedido ao aluno a opção de cursar ou não a disciplina.

O ir-e-vir da Sociologia no Ensino Médio impediu que se desenvolvesse uma tradição de ensino desta ciência nas escolas. Ficaram prejudicados as pesquisas nesta área, o desenvolvimento de metodologias adequadas, de textos didáticos sérios, de recursos didáticos. A formação do professor desta área ficou empobrecida, diante da falta de perspectiva de atuação e da pouca atenção e investimento que os cursos de graduação em Ciências Socais depositavam nas licenciaturas (CORREA, 2004, p. 238). 
Tratando da qualificação do professor de sociologia, Sousa (2016) assevera que o quadro de professor de Sociologia não qualificado está presente em várias cidades do país, entre elas Uberlândia (MG), onde, em 2001, dos 22 professores que lecionavam Sociologia, somente 11 eram habilitados. Em Londrina (PR), dos professores de Sociologia que ministravam Sociologia em 1999, 65\% não são formados em Ciências Sociais. Em Natal (RN), em 2004, das 35 escolas que ministravam a disciplina de Sociologia, apenas 4 contavam com professores formados em Ciências Sociais. Essa realidade não é diferente da cidade de Picos (PI), onde a pesquisa foi realizada em 2017: das 5 escolas pesquisadas, só 1 professor de Sociologia tinha formação em Ciências Sociais.

Ainda segundo Sousa (2016), em se tratando do professor de Sociologia, é preciso desenvolver programas de formação docente em Ciências Sociais e de favorecimento de suas condições de trabalho, levando-se em conta o papel da Sociologia no Ensino Médio. Outra questão a ser considerada está relacionada à imprecisão dos conteúdos a serem trabalhados por esses docentes e às competências a serem desenvolvidas pelos educandos, conforme orienta a Base Nacional Comum Curricular (BNCC), uma vez que, no texto da LDB, é destacado que a referida disciplina deve preparar os alunos para o exercício e a construção da cidadania, porém, não esclarece os meios, nem de que forma os professores devem atender a esse requisito.

Essas discussões geram questionamentos sobre como os professores de Sociologia trabalham com a concepção de cidadania e como o ensino deste componente curricular pode contribuir para a formação cidadã dos educandos. Sabe-se que, para atender a essa perspectiva, é necessário que as práticas educativas ultrapassem a proposta de educação bancária, em que o educando é visto como mero receptor de conteúdo (FREIRE, 1997).

Esta discussão é pertinente tendo em vista que os conhecimentos de Sociologia, enquanto conteúdos curriculares, têm uma tarefa social e transformadora a exercer; não se trata de depositar nos alunos teorias não refletidas, que apenas diminuem as oportunidades de reflexão e formação crítica, deixando de cumprir um dos objetivos da Sociologia, que é despertar a consciência crítica e reflexiva do aluno.

Diante disso, o trabalho de qualquer educador deve ser permeado por uma compreensão histórica da sociedade para que possa desenvolver uma prática contextualizada, possibilitando construir um sentido para todos os aspectos da experiência vivida por ele e pelos alunos (SOUSA, 2012).

Sobre o significado de cidadania, Covre $(1991$, p. 9) aponta que "[...] ser cidadão significa ter direitos e deveres, ser súdito e soberano". Ou seja, ser possuidor de direitos não se restringe apenas ao direito de votar, é muito mais amplo, é um ato crítico, político e social. Segundo Oliveira (2007, p. 58), "Cidadania significa compromisso ativo, responsabilidade. Significa fazer diferença na sua comunidade, na sua sociedade, no seu país". Ou seja, é uma ação inerente à educação, cabe à Sociologia proporcionar conhecimentos necessários ao exercício da cidadania, mostrando aos sujeitos, por meio dos saberes teóricos, que os seus direitos não devem ser violados, a fim de desenvolverem uma consciência política e social, como agentes de conquistas, em vez de meros reprodutores ou receptores.

A Sociologia como uma disciplina com capacidade de trabalhar o senso crítico pode contribuir para um olhar sociológico dos educandos, não se trata de decorar as teorias desse campo, porém, de colocar em ação o aprendizado. Entende-se ela pode contribuir para uma formação mais humana e para um raciocínio crítico e sistemático da realidade, pois só através dessa postura os alunos se tornarão protagonistas de suas histórias, perceberão os problemas sociais dos seus contextos e passarão a intervir na construção da sociedade, seja através de opiniões, reivindicações 
diante das injustiças ou de ações políticas mediante os movimentos sociais (DAYRELL; REIS, 2007).

Nas Diretrizes Curriculares Nacionais para o Ensino Médio (DCNEM, 2006), a questão da cidadania é considerada quando afirma que a Sociologia e a Filosofia passam a estar presentes na área de Ciências Humanas e suas Tecnologias, para que se cumpra o que está expresso na LDB 9.394/96, no artigo 36, $3^{\circ}$ parágrafo. Santos (2002, p. 77) ressalta que:

[...] na perspectiva da Reforma do Ensino Médio, os conhecimentos sobre sociedade e homens derivados da Sociologia e demais Ciências Humanas ajudariam na formação de um cidadão, tendo em vista as exigências postas pelo atual contexto de transformações sociais e econômicas. Contexto no qual o educando deverá atuar de forma reflexiva, solidária, responsável, criativa, autônoma e participativa.

Dessa forma, o conceito de cidadania é explícito numa das competências gerais da Base Nacional Comum Curricular (BNCC), entendida como "[...] agir pessoal e coletivamente com autonomia, responsabilidade, flexibilidade, resiliência e determinação, tomando decisões com base em princípios éticos, democráticos, inclusivos, sustentáveis e solidários." (BNCC, 2018, p.10). Coaduna com a perspectiva mencionada por Oliveira (2007), que entende cidadania como um compromisso ativo e responsável para a construção de uma sociedade mais justa e democrática. Portanto, essa competência está intrínseca ao objetivo da Sociologia, ou seja, preparar os discentes para a vivência na sociedade de maneira responsável e consciente de seus deveres e direitos, reivindicando-os quando necessário, problematizando os processos que resultam em desigualdades políticas, econômicas e sociais.

Em suma, a ideia de cidadania é destacada como algo necessário para a formação do novo cidadão, que deve agir e intervir nesse contexto, marcado por várias transformações, exigindo profissionais qualificados para darem conta dessas demandas. Nesse sentido, o professor cumprirá um papel político no ensino da Sociologia, para que consiga desnaturalizar as formas sociais que se instauram dentro da sociedade, buscando despertar um olhar crítico sobre a realidade social e promovendo a formação cidadã, que lhes possibilitarão exercer, de fato, sua cidadania e contribuir para sua inserção e mobilidade social.

\section{METODOLOGIA}

Os resultados apresentados neste artigo foram obtidos por meio de uma metodologia de pesquisa de abordagem qualitativa, desenvolvida entre novembro de 2015 e abril de 2017. Inicialmente, foi realizado um levantamento bibliográfico, que possibilitou construir o aporte teórico para a fundamentação deste estudo. Posteriormente, realizou-se uma visita à $9^{a}$ Gerencia Regional de Educação de Picos-PI, para selecionar as escolas que trabalham com a disciplina de Sociologia, sendo indicadas 5, assim nominadas: Unidade Escolar Polivalente Vidal de Freitas, CETI Marcos Parente, Unidade Escolar Miguel Lidiano, Unidade Escolar Coronel Francisco Santos e Escola Normal Oficial de Picos, todas da rede Estadual de ensino da cidade de Picos-PI.

As escolas pesquisadas são classificadas em média e pequeno porte pela Secretaria de Educação e Cultura. Trabalham com ensino fundamental e médio, apenas a Escola Normal Oficial de Picos oferece unicamente o ensino médio. No conjunto das escolas, são 734 alunos matriculados, sendo 497 no $2^{\circ}$ e $3^{\circ}$ ano do ensino médio. A disciplina de Sociologia faz parte do 
currículo dos dois últimos anos da referida etapa de ensino, critério adotada para a seleção das escolas e turmas investigadas. No entanto, percebe-se que o currículo estava em desacordo com o que propõe a Lei 11.684, de 2 de junho de 2008, que estabelece a obrigatoriedade das disciplinas de Sociologia e Filosofia nas três séries de todas as escolas do ensino médio no Brasil

Realizou-se a imersão no campo da pesquisa, que se constituiu em aplicação de questionário para 50 estudantes do $2^{\circ}$ e $3^{\circ}$ ano do ensino médio das escolas selecionadas. O questionário foi entregue na chegada da escola para os alunos que concordaram em participar da pesquisa, e foram recolhidos no final da aula, sendo 18 do sexo masculino e 32 do sexo feminino, com idade entre 15 e 20 anos.

Ao longo do texto, os alunos participantes da pesquisa são identificados pelos seguintes códigos: "A", acompanhado de um algarismo, o que representa o "Aluno", em uma determinada sequência numérica. Assim, preserva-se a sua identidade e, ao mesmo tempo, facilita-se a sua identificação. A pesquisa seguiu os procedimentos éticos previstos na Resolução 466/2012, do Conselho Nacional de Saúde (CNS), apresentando-se aos participantes o termo de consentimento livre e esclarecido.

Escolheu-se como instrumento de coleta de dados o questionário estruturado, por ser um instrumento que objetiva "traduzir os objetivos da pesquisa em questões especificas" (GIL, 2010, p.121), composto por questões abertas e fechadas, com a finalidade de colher informações sobre o significado da Sociologia na formação da cidadania e se a aulas de Sociologia contribuíram para despertar a consciência crítica dos alunos pesquisados.

Para a análise dos dados coletados, buscou-se apoio metodológico em procedimentos da Análise de Conteúdo na perspectiva de Bardin (2011), que possibilita ao pesquisador compreender a intencionalidade comunicativa, sendo que a atribuição basilar da análise de conteúdo é, sobretudo, o desvendar crítico. Para a autora, "[...] a análise de conteúdo é um conjunto de instrumentos de cunho metodológico em constante aperfeiçoamento, que se implicam os discursos (conteúdos e continentes) extremamente diversificados" (BARDIN, 2011, p. 15).

Essa técnica presume a análise de significados, isto porque parte de uma descrição objetiva, sistemática e qualitativa dos dados obtidos em comunicações. Produzir inferências em análise de conteúdo tem um significado bastante explícito e prevê a comparação dos dados com os pressupostos teóricos de diferentes concepções de mundo, de indivíduo e de sociedade (BARDIN, 2011).

Conforme os pressupostos de Bardin (2011), a análise dos dados foi desenvolvida em três etapas: 1) Pré-análise; 2) Exploração do Material; 3) Tratamento dos Resultados, a inferência e a interpretação. Na pré-análise, ocorreu a seleção e organização dos questionários, por meio da leitura flutuante das respostas, verificando-se se as informações estavam coerentes com o objetivo da pesquisa. A exploração do material foi demorada e exaustiva, incidindo em operações de codificação, e neste caso optou-se pela porcentagem.

Dando prosseguimento à análise, os dados foram traduzidos e agrupados dentro das categorias temáticas, que foram as seguintes: a) concepções de cidadania; e b) contribuição da Sociologia na formação crítica dos discentes. Essas categorias surgiram no decorrer das leituras e com a construção do referencial teórico, e foram utilizadas na elaboração do questionário. Por fim, as inferências e interpretações produzidas nas análises e em comparação aos pressupostos teóricos estão dispostas na próxima seção deste artigo em formato de resultados e discussões. 


\section{RESULTADOS E DISCUSSÃO}

A partir das informações obtidas com a aplicação do questionário, as respostas dos 50 alunos participantes da pesquisa foram analisadas com base em duas categorias: concepções de cidadania e contribuição da Sociologia na formação crítica. Inicialmente, perguntou-se aos alunos se consideram os assuntos estudados nas aulas de Sociologia como importantes e o porquê de assim os qualificarem. Verifica-se que $56 \%$ dos alunos responderam que sim, justificando que a Sociologia é importante porque permite compreender e analisar a sociedade.

A sociologia é importante, pois além de ajudar a compreender e analisar a nossa sociedade, nos ajuda a entender questões como: desigualdades sociais, direitos e deveres, as relações de poder, as estruturas sociais, contribuindo para uma formação social (A6, 2016).

Os conhecimentos sociológicos na visão de A6 têm um sentido de desnaturalizar a realidade social, já que possibilita entender os fatores e os problemas que cercam a vida social. Verifica-se que os conhecimentos desse componente possibilitam uma ampliação na formação dos educandos e podem contribuir para o desenvolvimento de uma consciência sociológica.

Representa um divisor de águas, pois antes da Sociologia existia um ser alienado e inconsciente, depois dela, uma cidadã ciente de seus direitos e deveres da sociedade (A12, 2016).

Ou seja, a aluna A12 entende a Sociologia como um divisor de águas, metáfora, e nesse contexto significa mudança marcante, que pode acontecer quando o sujeito se apropria dos conhecimentos sociológicos e sabe utilizá-los em favor próprio, pois acontece uma mudança de comportamento, uma vez que consegue interpretar a vida social, os fatores que a dinamizam e até interferir para que aconteça, de fato, uma transformação social significativa e mais justa.

Diante disso, Berger (1986, p. 31) afirma que "O fascínio da Sociologia está no fato de que sua perspectiva nos leva a ver sob nova luz o próprio mundo em que todos vivemos. Isto também constitui uma transformação da consciência". Constata-se que a Sociologia tem um papel importante no processo de formação dos alunos, pois viabiliza aos educandos estudarem os fenômenos sociais de maneira científica.

Prosseguindo com as análises, 34\% dos alunos responderam que a Sociologia ajuda a despertar o senso crítico. Como explica Giddens (apud SANTOS, 2002, p. 15), "[...] a disciplina de Sociologia teria implicações práticas importantes para a nossa vida. Trata de uma ciência que pode contribuir para uma crítica social e para uma reforma da prática social”. Percebe-se que o componente curricular tem a finalidade de instigar a criticidade nos sujeitos e formá-los para uma prática social crítica, contribuindo, assim, para formação da cidadania dos alunos do ensino médio.

Dos demais alunos, $10 \%$ responderam que essa disciplina é importante, "[...] porque ajuda as pessoas a conviverem em sociedade, respeitando as diferenças uns dos outros ” (A38, 2016). Há uma compreensão da disciplina para o desenvolvimento de relações sociais inclusivas, o que permite entender que a Sociologia não fica apenas no campo da teoria, mas deve efetivar-se na prática, uma vez que instiga os alunos a mudarem suas atitudes, evitando comportamentos de preconceito e discriminação. De acordo com Damasceno (2001, p. 22), “[...] a escola possibilita a convivência com a diferença, de uma forma qualitativamente diferente da família. [...] Possibilita lidar com a subjetividade, havendo oportunidade para os alunos falarem de si, trocarem ideias, 
sentimentos". Portanto, a Sociologia provoca debates sobre as diversas culturas, etnias e confronta os valores sociais. Essas discussões representam um espaço formativo pessoal e social indispensável para construir-se como cidadão.

Perguntou-se aos alunos quais assuntos são abordados nas aulas de Sociologia: 56\% dos questionados destacaram temas diversificados, como educação, cidadania, relações sociais, religião, política, racismo, democracia, sociedade, desigualdade; 36\% mencionaram o tema sociedade contemporânea; $4 \%$ falaram que, nas aulas de Sociologia, são tratados temas relacionados à convivência social, transformações sociais e sobre a importância dos movimentos sociais; e, 4\% não souberam responder.

A Sociologia destaca-se por analisar de maneira ampla e reflexiva a vida moderna, e os temas elencados pelos estudantes abrangem esse contexto atual. Além disso, Sousa (2012) destaca que o ensino de Sociologia deve estar mais interessado em ensinar ao aluno um pensamento sociológico sobre temas e situações em que os jovens estejam envolvidos e desejosos de discutir.

Ao procurar saber como são as aulas de Sociologia, verificou-se que $90 \%$ dos alunos consideram "[...] que são boas, porque aprendem a ter senso crítico, dar opiniões, porque os professores explicam bem e permitem a participação" (A27, A48, 2016), ao passo que 10\% consideram como "[...] razoáveis, por ser entediante" (A32, 2016). Evidencia-se que, para quase totalidade dos alunos investigados, existe uma boa aceitação das aulas de Sociologia, porque ela desperta o senso crítico e os professores têm boa didática e interagem com os alunos.

Quando investigados se os estudos e as discussões realizadas nas aulas de Sociologia despertam uma reflexão crítica, todos concordaram que sim: $20 \%$ disseram que esse processo reflexivo acontece "[...] por meio dos temas debatidos durante as aulas, uma vez que, ajudam a entender certos acontecimentos do nosso país" (A02, A17, A22,2 016); 30\% consideram ser importante porque "[...] despertam o senso crítico, através da construção de novos conhecimentos, no que diz respeito aos nossos direitos e deveres, ajuda na compreensão dos valores dentro da sociedade, questiona a desigualdade social" (A03, A09, A37, 2016); e 10\% acreditam que "[...] ajuda a entender os movimentos sociais" (A24, A4, 2016).

Nesse sentido, Tomazi e Lopes Júnior (2004, p. 73) asseveram que

[...] um pensamento sociológico sobre temas e situações em que os nossos jovens alunos estejam envolvidos e desejosos de discutir e não somente preocupados em passar conceitos clássicos de autores clássicos que podem até fazer com que os alunos aprendam o que é Sociologia e seus conceitos fundamentais, mas que no final não são capacitados a "pensar" sociologicamente.

Segundo 96\% dos alunos, a Sociologia tem contribuído para a formação de um pensar sociológico, seja no que diz respeito aos conhecimentos adquiridos na compreensão dos valores sociais e/ou dos movimentos sociais, possibilitando-lhes uma compreensão mais ampla dos seus direitos e deveres, bem como das desigualdades sociais que marcam as sociedades movidas pelo capitalismo.

Para finalizar, perguntou-se aos alunos qual o significado da Sociologia em suas formações como cidadãos ou cidadãs. Assim, 18\% dos alunos responderam que "[...] significa uma fonte de conhecimento, já que passamos a entender as profundas mudanças que acontecem na sociedade e podemos até melhorá-la" (A10, A13, A50, 2016); 15\% falaram que "[...] significa uma forma de expressão, em que podemos manifestar nossas opiniões no que achamos certo ou errado" (A29, A38, 2016), ou seja, ajuda na construção dos pensamentos e representações dos educandos; $15 \%$ 
que "[...] ensina a lutar pelos direitos de um cidadão" (A20, A31, A40, 2016); e apenas 2\% acreditam que [...] a Sociologia não ajuda a se tornar um cidadão, pois são apenas teorias" (A21, 2016).

Para Covre (1991, p. 10), "Só existe cidadania se houver a prática da reivindicação, da apropriação de espaços, da pugna para fazer valer os direitos do cidadão". Sabe-se que a educação tem um papel importante na formação desses cidadãos e os conhecimentos sociológicos são fundamentais, uma vez que mostram teorias que contemplam a realidade social, assim, é importante saber que os alunos pesquisados conseguem ter essa compreensão.

\section{CONSIDERAÇÕES FINAIS}

O trajeto da disciplina de Sociologia nas escolas do ensino médio brasileiro tem uma história de mais de 100 anos de inclusão e exclusão, a sua presença e a ausência nessa etapa de ensino sempre estiveram relacionadas à situação política e social do país e ao grau de mobilização dos movimentos sociais, em que seus percursores viam a Sociologia como ciência que poderia ajudá-los a analisar e entender a sociedade. Assim, considera-se que a implantação e efetivação da Sociologia no currículo para formação cidadã dos alunos jovens brasileiros têm sido uma luta árdua, na qual muitos debates e questionamentos foram lançados sobre a inclusão dessa ciência como disciplina do ensino médio.

No decorrer das análises dos dados, evidencia-se que a ideia da cidadania ou formação do cidadão está presente nos depoimentos dos alunos das escolas públicas pesquisadas. Obtiveram-se informações que revelaram a Sociologia como um componente essencial para a formação da cidadania, pois possibilita o crescimento do aluno como um cidadão ativo, crítico e reflexivo.

Evidencia-se, ainda, que a disciplina de Sociologia despertou juntos aos alunos das escolas pesquisadas uma compreensão crítica da sociedade na qual estão inseridos, contribuindo para uma consciência politizada, a partir de uma postura crítica que proporciona a superação do senso comum. Ou seja, a Sociologia firma-se como um instrumento de conscientização, sendo os conhecimentos sociológicos necessários ao exercício da cidadania, como determina o artigo $36,3^{\circ}$ parágrafo, da LDB, 9.394/96, quando diz que os alunos, ao término do ensino médio, devem demonstrar domínio dos conhecimentos de Filosofia e Sociologia necessários ao exercício da cidadania.

Enfim, este estudo contribui para a discussão acerca da inclusão da Sociologia no ensino médio como componente obrigatório, pois seu ensino é fundamental, como pôde-se constatar nas percepções dos alunos de ensino médio participantes desta pesquisa, desempenhando um papel importante na construção cidadã dos educandos, possibilitando a estes uma compreensão melhor da sociedade em que vivem, tornando-os cidadãos mais conscientes da legitimidade de seus direitos e deveres.

\section{REFERÊNCIAS}

BARDIN, Laurence. Análise de Conteúdo. 70. ed. Lisboa, 2011.

BRASIL. Lei de Diretrizes e Bases da Educação Nacional: Lei 9394/96. Brasília, 1996.

BRASIL. Base Nacional Comum Curricular. Ministério da Educação, Brasília, DF: MEC, 2018.

BERGER, Peter. Perspectivas sociológicas: uma visão humanística. Petrópolis: Vozes, 1986.

COVRE, Maria de Lourdes Manzini. O que é cidadania. 1. ed. São Paulo: Brasiliense, 1991. 
CORREA, Lesi. Laboratório de Ensino de Sociologia. In: CARVALHO, Lejeune (org.). Sociologia e Ensino em Debate: experiências e discussões de sociologia no ensino médio. Cad. Cedes, Campinas, v. 31, n. 85, p. 359-382, set./dez. 2011.

DAMASCENO, Maria Nobre. Trajetória da juventude: caminhos, encruzilhadas, sonhos e expectativas. In: DAMASCENO, Maria Nobre et al. (org.). Trajetórias da juventude. Fortaleza: LCR, 2001. p. 9-24. (Coleção Diálogos Intempestivos).

DAYRELL, Juarez; REIS, Juliana Batista. Juventude e Escola: Reflexões sobre o Ensino da Sociologia no Ensino médio. In: CONGRESSO BRASILEIRO DE SOCIOLOGIA, 13., 2007, Recife. Anais... Recife-PE: Sociedade Brasileira de Sociologia, 2007. p. 1-17.

FREIRE, Paulo. Pedagogia do Oprimido. 17. ed. Rio de Janeiro: Paz e Terra, 1997.

GIL, Antônio Carlos. Métodos e técnicas de pesquisa social. 6. ed. São Paulo: Atlas, 2010.

OLIVEIRA, Dalta Motta. A prática pedagógica dos professores de Sociologia: entre a teoria e a prática. 2007. 111 f. Dissertação (Mestrado em Educação) - Universidade Estácio de Sá, Rio de Janeiro, 2007.

SANTOS, Mário Bispo dos. A Sociologia no Ensino Médio: o que pensam os professores da rede pública do Distrito Federal. Dissertação (Mestrado em Sociologia) - Universidade de Brasília, Brasília, 2002.

SOUSA, Maria das Dores. Identidade e docência: o saber-fazer do professor de sociologia das escolas públicas estaduais de Picos - PI. Tese (Doutorado em Educação) - Universidade Federal do Rio Grande do Norte, Natal-RN, 2012.

SOUSA, Maria das Dores. Identidade e docência: o professor de sociologia do ensino médio. 1. ed. Curitiba: Appis, 2016.

TOMAZI, Nelson Dacio; LOPEZ Júnior, Edimilson Lopez. Uma Angústia e duas Reflexões. In: CARVALHO, L.M.G. de (org.). Sociologia e ensino em debate: experiências e discussões de sociologia no ensino Médio. Ijuí: Ed. Unijuí, 2004. p. 61-75.

\section{Informações do(a)(s) autor(a)(es)}

Maria das Dôres de Sousa

Afiliação institucional: Universidade Federal do Piauí (UFPI)

E-mail: mariadasdoressousa@hotmail.com

ORCID: https://orcid.org/0000-0002-5010-9771

Link Lattes: https://lattes.cnpq.br/9867735393590059

Luciana Silva Dias

Afiliação institucional: Universidade Federal da Paraíba Afiliação institucional (UFPI)

E-mail: lucianadaisibn@gmail.com

ORCID: https://orcid.org/0000-0001-9799-8628 
Link Lattes: http://lattes.cnpq.br/895916677314290

Douglas Pereira da Costa

Afiliação institucional: Universidade Federal do Piauí (UFPI)

E-mail:

ORCID: https://orcid.org/0000-0003-0706-7163

Link Lattes: http://lattes.cnpq.br/6834502765479639 